\section{Glued posterior chamber IOL in eyes with deficient capsular support: a retrospective analysis of 1-year post-operative outcomes}

DA Kumar, A Agarwal, G Prakash, S Jacob, Y Saravanan and A Agarwal
Eye (2010) 24, 1143-1148; doi:10.1038/eye.2010.10;

published online 12 February 2010

Keywords: glued IOL; sutureless IOL; IOL in deficient capsule

Introduction

Intraocular lens (IOL) implantation in eyes with deficient capsular support has been at the forefront of surgical research for many years now. IOL implantation in the ciliary sulcus is possible in eyes with adequate anterior capsular support. ${ }^{1}$

However, in eyes with deficient anterior capsular rim, anterior chamber (AC) IOL, iris claw lenses, or sutured scleral-fixated (SF) IOL are usually performed. ${ }^{2-8}$ Fibrin glue-assisted posterior chamber (PC) IOL implantation is a new technique started in December 2007 in eyes with deficient capsular support. ${ }^{9-12}$ The purpose of this article is to evaluate the post-operative outcome, namely, visual prognosis and complication profile, of eyes operated using this technique at the end of 1 year.

\section{Materials and methods}

In this retrospective case series, 53 eyes of 53 patients who underwent fibrin glue-assisted posterior chamber IOL implantation ${ }^{9}$ were analysed after 1 year. All eyes operated using this procedure from December 2007 to May 2008 were included and followed up for 12 months. The selection criteria was eyes with deficient capsular or sulcus support in which implantation of PC IOL was not possible, $>180$ degrees subluxated cataract, and aphakia.
Dr Agarwal's Eye Hospital and Eye Research Centre, Chennai, India

Correspondence: A Agarwal, Dr Agarwal's Eye Hospital and Eye Research Centre, 19 Cathedral road, Chennai 600 086, India Tel: + 91442811 6233; Fax: + 914428115871 E-mail: dragarwal@ vsnl.com

Received: 13 October 2009 Accepted in revised form: 21 December 2009 Published online: 12 February 2010 
The study was approved by our institutional review board.

On each follow-up visit (1, 3, 6, and 12 months), the following parameters were assessed: uncorrected visual acuity (UCVA) and best spectacle-corrected visual acuity (BCVA), refraction, intraocular pressure (IOP, noncontact tonometry), slit lamp biomicroscopy, dilated fundus examination, specular microscopy (SP-2000P, Topcon, Tokyo, Japan), and AC cellular reaction grading with SUN (Standardization of Uveitis Nomenclature) classification. ${ }^{13}$ All the pre-operative parameters were compared with 1-year post-operative parameters. Ultrasound biomicroscopy (UBM) (Appasamy associates, Chennai, India) was carried out to document the IOL position and sclerotomy ports. A line was drawn along the limbus, marking it as the plane of reference for the optic position in the UBM and a second line was drawn along the long axis of the IOL optic. The optic was considered to be not tilted when the reference line along the limbus and the IOL optic were parallel. ${ }^{14}$ According to the equation of straight line, $y=m x+c$, the slope of the line through limbus and IOL was determined.

Serial digital slit lamp images of the eye with full pupillary dilatation were taken to assess IOL centration. An image processing with Matlab version 7.1 (Mathworks Inc, Natick, MA, USA) was carried out to quantify decentration. The geometric centre of the limbus (a) (Figure 1) and the IOL optic (a1) was deducted. The distance $(r)$ between the two geometric points was calculated in $\mathrm{mm}$ on each visit. The amount of decentration of the geometric center of the IOL optic with respect to the $x$ axis and $y$ axis of a two dimensional Cartesian system (the coronal plane) was determined. ${ }^{15}$ If there was a significant change in the geometric centre of the IOL optic and the limbus in the follow up visit, the
IOL was considered as decentered. Central macular thickness (CMT) was measured using posterior segment Stratus Optical Coherence Tomography (OCT) (Carl Zeiss Meditec, Dublin, CA, USA). The distance between the iris and the IOL optic was calculated using the anterior segment Visante OCT (Carl Zeiss Meditec). A serial slit lamp examination at $\times 20$ magnification under retro illumination in a dilated pupil with the patient's gaze focussed at a fixation target was performed to evaluate pseudophakodonesis.

\section{Statistical analysis}

Data were entered in a Microsoft Excel Sheet (Microsoft: Microsoft Corp, USA), and was analysed using SPSS version 16.1 (SPSS, SPSS Inc, Chicago, Illinois).

Differences were considered statistically significant at $P<0.05$. Wilcoxon signed-rank test for related samples, Mann-Whitney $U$-test for comparing two groups, and Kruskal-Wallis to analyse more than two groups were used.

\section{Results}

Out of 53 patients, there were 23 female and 30 male patients. The mean age in years was $50.63 \pm 15.75$. In total, $35(66 \%)$ and $18(33.9 \%)$ out of 53 eyes underwent the surgery as primary and secondary procedure, respectively. The most common indication was intraoperative posterior capsular rupture with absent sulcus support $(35.8 \%)$ followed by aphakia (33.9\%) and subluxated cataract $(30.1 \%)$. A single-piece PMMA IOL (Appasamy associates), with optic size $6.5 \mathrm{~mm}$ and overall diameter of $13 \mathrm{~mm}$, was implanted in all the eyes. a

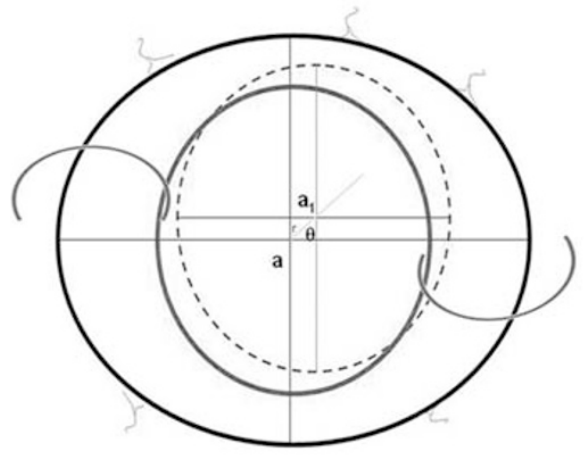

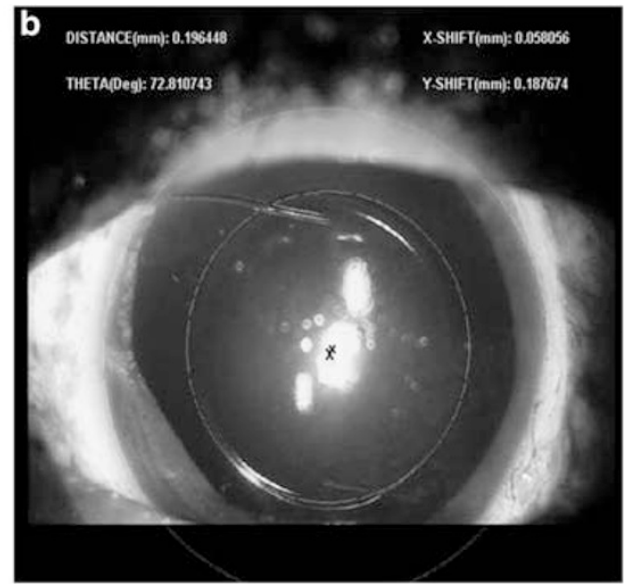

Figure 1 (a) Decentration of the geometric center of the IOL optic $\left(\mathrm{a}_{1}\right)$ with respect to limbus (a) was determined as $r$ (mm). (b) Mild decentration detected in an eye in the early post-operative period. 
SRK II formula was used for IOL power calculation. Postoperative refractive error was targeted for emmetropia.

The mean pre-operative UCVA in LogMAR was $-0.90 \pm 0.70$ and the mean post-operative UCVA was $-0.23 \pm 0.13$. The mean post-operative BCVA was $-0.13 \pm 0.15$. There was significant improvement in UCVA (Wilcoxon signed-rank test, $P=0.000$ ) and BCVA $(P=0.000)$. The mean spherical equivalent at 1 -year follow-up was $-0.46 \pm 1.2 \mathrm{D}$ and the mean prediction error was $0.46 \pm 1.2 \mathrm{D}$. The average post-operative astigmatism was $-1.6 \pm 1.4 \mathrm{D}$. A total of $27(50.9 \%)$ out of 53 eyes showed improvement, as compared with preoperative BCVA (Figure 2). Loss of BCVA ( $\leqslant 2$ lines) was seen in six $(11.3 \%)$ eyes (Figure 2$)$. The documented loss of BCVA in the 1-year post-operative period was due to macular pathology such as healed macular oedema or age-related macular degeneration changes. There was no significant difference in post-operative (1 year) BCVA between primary and secondary procedures (MannWhitney $U$-test, $P=0.279)$. There was significant difference (Kruskal-Wallis, $P=0.002$ ) in post-operative BCVA (1 year) between the three groups (that is, PCR, subluxated, and aphakia).

The central hexagonal endothelial cells were analysed. The mean area analysed was $434.9 \pm 163 \mathrm{~mm}^{2}$ pre-operatively and $442.9 \pm 161 \mathrm{~mm}^{2}$ post-operatively. The mean pre-operative and post-operative specular count was $2217 \pm 320.1$ and $2099 \pm 318.7$ cells per $\mathrm{mm}^{2}$ respectively. There was significant reduction in postoperative specular count (Wilcoxon signed-rank test, $P=0.000)$. The percentage $(\%)$ loss of endothelial cells from the pre-operative to 1-year post-operative (1 year) period was $5.23 \pm 3.4 \%$. The mean coefficient of variation (CV) pre-operative and post-operative was 19.1 and 19.7, respectively. No significant difference $(P=0.964)$ in $\mathrm{CV}$ was noted. The mean IOP recorded at post-operative 1 year period was $14.37 \pm 3.6 \mathrm{~mm} \mathrm{Hg}$. There was no statistically significant difference (Wilcoxon signed-rank test, $P=0.447$ ) in IOP observed from the pre-operative to the post-operative (1 year) period. A grade II AC cellular reaction resolving within $48 \mathrm{~h}$ of medical management was seen in 3 out of 53 eyes on day 1 of the post-operative period. No recurrent uveitis was recorded in any of the operated eyes in the follow-up. There were no signs of clinically active uveitis (AC cells, flare, or keratic precipitates) observed at the follow-up. Iridodonesis was seen in $18.8 \%$ of the eyes (10 out of 53 eyes) and clinical pseudophakodonesis was not observed in any of the eyes. UBM showed no vitreous incarceration or uveal tissue prolapse in the sclerotomy ports. The post-operative mean CMT at 1 year was $190.8 \pm 5.9 \mu \mathrm{m}$. There was no post-operative vitritis or endophthalmitis seen in any of the patients. No retinal break or retinal detachment was documented on serial fundus examination. Table 1 shows the post-operative profile of all the eyes at 1 year.

The absolute mean slope of the line through the limbus was $0.03 \pm 0.09$ and the absolute mean slope of the line

Table 1 Complications of glued IOL

\begin{tabular}{lc}
\hline Complications profile & 1-year follow-up $(\mathrm{n}=53)$ \\
\hline $\begin{array}{l}\text { Intra operative; } \mathrm{n}(\%) \\
\text { Hyphema }\end{array}$ & $2(3.7 \%)$ \\
& \\
Post-operative; $\mathrm{n}(\%)$ & \\
Early $(<2$ months) & $3(5.6 \%)$ \\
$\quad$ Decentration & $0(0.0 \%)$ \\
Post-operative glaucoma & \\
& \\
Late (>2 months) & $2(3.7 \%)$ \\
Pigment dispersion & $0(0.0 \%)$ \\
Retinal tear & $0(0.0 \%)$ \\
Retinal detachment & $0(0.0 \%)$ \\
Non-resolving vitreous & \\
haemorrhage & $0(0.0 \%)$ \\
Recurrent uveitis & $4(7.5 \%)$ \\
Healed macular oedema & $0(0.0 \%)$ \\
Pseudophakic bullous keratopathy &
\end{tabular}

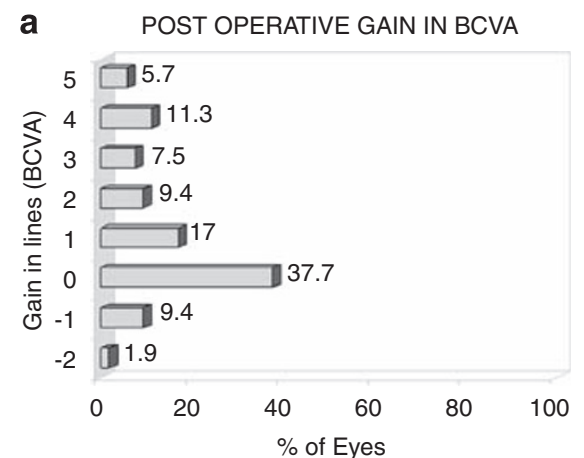

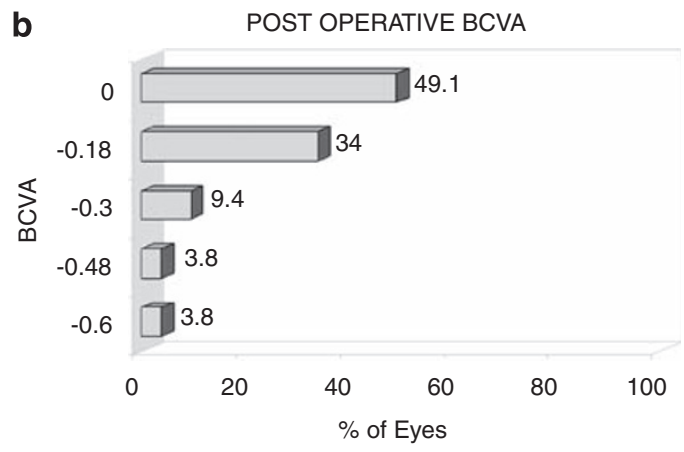

Figure 2 (a) Bar diagram showing the gain in post-operative BCVA. (b) Bar diagram showing the distribution of 1-year post-operative BCVA. 
through the IOL optic was $0.03 \pm 0.1$. The mean ratio of the slope was $1.04 \pm 0.28 \mathrm{~mm}$. The mean distance between the iris and the IOL was $0.99 \pm 0.2 \mathrm{~mm}$ in OCT. On calculating the distance $(r)$ between the two geometric points of the limbus and IOL optic, the mean $r$ at last follow-up was $0.09 \pm 0.2 \mathrm{~mm}$. The mean $x$ and $y$ axis shift was $0.091 \pm 0.19 \mathrm{~mm}$ and $0.019 \pm 0.05 \mathrm{~mm}$, respectively. There was no significant change in $x$ axis shift in the follow-up in the post-operative period (Wilcoxon signedrank test, $P=1.00)$.

\section{Discussion}

There have been sutureless scleral fixation techniques ${ }^{16,17}$ for PC IOL implantation in eyes with inadequate support in the recent past. Our technique differed from other sutureless methods by the externalisation of haptics under the scleral flaps instead of sclerotomy ${ }^{16}$ and also the use of fibrin glue. We preferred biological glue to stick the flaps, as it prevents formation of subconjunctival bleb, which may happen when the scleral flaps are sutured. The risk of bleb-related endophthalmitis ${ }^{18}$ and suture-related complications ${ }^{19-21}$ are less when the flaps are closed with fibrin glue. Moreover, this method can be performed in both rigid and three-piece foldable IOL. Hence, there is no need for specially designed SF IOL. We now prefer to use a three-piece foldable or non-foldable IOL, as the optic haptic junction does not break, which can happen when implanting a single-piece non-foldable IOL. With a three-piece foldable IOL, the incision size is reduced as the IOL can be injected.

Evereklioglu et $a l^{22}$ reported that sutured scleralfixated PC IOL seemed to provide a more favourable outcome and a lower complication rate than the openloop AC IOL in complicated cataract cases. A study by Donaldson $e t a l^{23}$ has shown no significant differences in outcome on comparing AC IOLs with sutured PC IOLs in complicated cataract extraction with poor capsular support. Bellucci et $a l^{24}$ have shown a complication rate of $6 \%$ in both AC IOL and sutured SF IOL, whereas more intraoperative and post-operative complications in SF IOL. Two separate reports from Kwong et $a l^{25}$ and Dadeya et $a l^{26}$ showed satisfactory outcome by AC IOL. On historical comparison with AC IOL, complication rate of 49 and $32 \%$ in primary and secondary implantation, respectively, of flexible open-loop AC IOLs was reported by Bayramlar et al. ${ }^{27}$ There are also reports showing endothelial loss and glaucoma after AC IOL implantation in the long-term follow-up. ${ }^{28,29}$

The haptics of the sulcus-fixated IOL in direct contact with the posterior surface of the overlying iris can cause focal iris atrophy and pigment dispersion. ${ }^{30}$ The IOL rotation and recurrent irritation of the iris are known to cause late UGH syndrome. ${ }^{31-33}$ Moreover, rubbing between the IOL optic and iris seems to contribute to the high flare counts in eyes with a sulcus-to-sulcus IOL fixation. ${ }^{33}$ In our series, consistent vault is maintained between the iris and the IOL, which we consider as one of the reasons for less post-operative uveitis and pigment dispersion. The pseudophakodonesis due to the oscillations of the fluids in the anterior and posterior segment is known to cause permanent damage on the corneal endothelium. ${ }^{34,35}$ However, there was no clinical pseudophakodonesis observed in our series and the endothelial cell loss was not more than any phacoemulsification procedure ${ }^{36}$ and less than an AC IOL implantation. ${ }^{29}$

Uthoff $e a^{37}$ showed suture erosion (17.9\%), cystoid macular oedema $(5.8 \%)$, retinal detachment $(1.4 \%)$, vitreous haemorrhage $(1.0 \%)$, and uveitis $(0.5 \%)$ in a 1-year post-operative outcome of sclera-fixated IOL. Vote et $a l^{38}$ showed the high risk of repeat surgeries in sutured SF IOL due to suture-related complications. It was noted that none of the intraoperative complications in our patients affected the final functional outcome. It has been shown that the overall length $(12.5-14.0 \mathrm{~mm})$ of the IOL

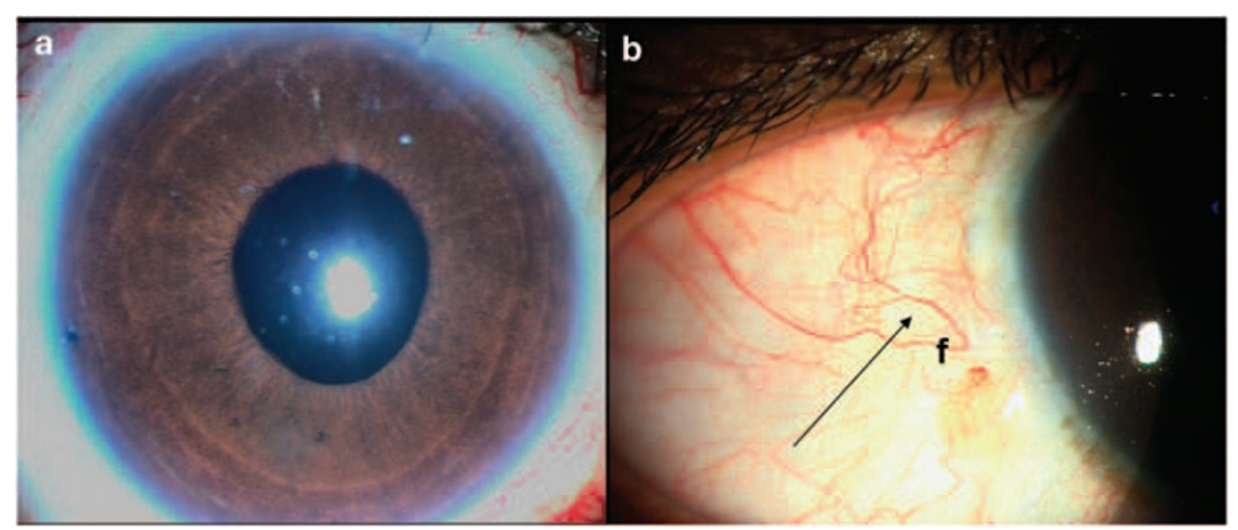

Figure 3 The 1-year post-operative clinical photograph showing (a) good IOL centration, (b) flap (f) apposition (shown with an arrow mark) and no haptic extrusion. 
helps ensure firm, stable fixation in the posterior chamber behind the iris, wherein the average diameter in emmetropic eyes is $\sim 13.0 \mathrm{~mm} .{ }^{39}$ In addition, the large optics lowers the risk of clinically significant postoperative decentration. As the overall diameter of the routine IOL is about $12-13 \mathrm{~mm}$, with the haptic being placed in its normal curved configuration and without any traction, there is no distortion or change in the shape of the IOL optic. The externalisation of the greater part of the haptics into the scleral tunnel along its curvature stabilises the axial positioning of the IOL preventing tilt. ${ }^{40}$ This is well shown by our 1-year follow-up results showing no haptic extrusion and good flap apposition (Figure 3).

The limitations of the study are: (1) we have analysed only the rigid IOLs and the post-operative outcomes of other IOL types need to be reported. (2) The follow-up is only 1 year and a longer follow-up might be required to confirm the long-term outcome. (3) A randomised control trial with SF and AC IOLs would be interesting in future, as the current study lacks a control group. Nevertheless, from the current study, it is considered that 1 year results of fibrin glue-assisted posterior chamber IOL implantation provided good visual prognosis with minimal complications in eyes with deficient capsular support. However, long-term follow-up would be required to determine the functional and anatomical results of the procedure.

\section{Summary}

What was known before

- Glued IOL surgical technique: Surgical technique with 6 weeks post-operative results were reported previously.

- Combined surgeries: Glued IOL with penetrating keratoplasty as a triple procedure in aphakic eyes with corneal pathology has been reported.

\section{What this study adds}

- Complication rate: Intra and post-operative complications in eyes with fibrin glue-assisted posterior chamber IOL implantation in long-term were studied.

- IOL centration analysis: IOL centration analysis of glued posterior chamber IOL was carried out using Matlab.

- Visual outcome: Analysis of post-operative visual outcome after 1 year in eyes with glued IOL implantation was carried out.

\section{Conflict of interest}

The authors declare no conflict of interest.

\section{References}

1 Taskapili M, Gulkilik G, Kocabora MS, Ozsutcu M, Yilmazli C, Kaya G. Comparison of sulcus implantation of single-piece hydrophilic foldable acrylic and polymethylmethacrylate intraocular lenses in eyes with posterior capsule tear during phacoemulsification surgery. Eur J Ophthalmol 2007; 17: 595-600.

2 Zeh WG, Price FW. Iris fixation of posterior chamber intraocular lenses. J Cataract Refract Surg 2000; 26: 1028-1034.

3 Bleckmann H, Kaczmarek U. Functional results of posterior chamber lens implantation with scleral fixation. J Cataract Refract Surg 1994; 20: 321-326.

4 Wagoner MD, Cox TA, Ariyasu RG, Jacobs DS, Karp CL, American Academy of Ophthalmology. Intraocular lens implantation in the absence of capsular support: a report by the American Academy of Ophthalmology. Ophthalmology 2003; 110: 840-859.

5 Grigorian R, Chang J, Zabrian M, Del Priore L. A new technique for suture fixation of posterior chamber intraocular lenses that eliminates intraocular knots. Ophthalmology 2003; 110: 1349-1356.

6 Monteiro M, Marinho A, Borges S, Ribeiro L, Correia C. Scleral fixation in eyes with loss of capsule or zonule support. J Cataract Refract Surg 2007; 33: 573-576.

7 Solomon K, Gussler JP, Gussler C, Van Meter WS. Incidence and management of complications of transsclerally sutured posterior chamber lenses. J Cataract Refract Surg 1993; 19: 488-493.

8 Hayashi K, Hayashi H, Nakao F, Hayashi F. Intraocular lens tilt and decentration, anterior chamber depth, and refractive error after trans-scleral suture fixation surgery. Ophthalmology 1999; 106: 878-888.

9 Agarwal A, Kumar DA, Jacob S, Baid C, Agarwal A, Srinivasan $S$. Fibrin glue-assisted sutureless posterior chamber intraocular lens implantation in eyes with deficient posterior capsules. J Cataract Refract Surg 2008; 34: 1433-1438.

10 Prakash G, Kumar DA, Jacob S, Kumar KS, Agarwal A, Agarwal A. Anterior segment optical coherence tomography-aided diagnosis and primary posterior chamber intraocular lens implantation with fibrin glue in traumatic phacocele with scleral perforation. J Cataract Refract Surg 2009; 35: 782-784.

11 Prakash G, Jacob S, Kumar DA, Narsimhan S, Agarwal A, Agarwal A. Femtosecond assisted keratoplasty with fibrin glue-assisted sutureless posterior chamber lens implantation: a new triple procedure. J Cataract Refract Surg 2009; 35(6): 973-979.

12 Nair V, Kumar DA, Prakash G, Jacob S, Agarwal A, Agarwal A. Bilateral spontaneous in-the-bag anterior subluxation of PC IOL managed with glued IOL technique: a case report. Eye Contact Lens 2009; 35(4): 215-217.

13 Jabs DA, Nussenblatt RB, Rosenbaum JT, Standardization of Uveitis Nomenclature (SUN) working group. Standardization of Uveitis Nomenclature for Reporting Clinical Data. Results of the First International Workshop. Am J Ophthalmol 2005; 140: 509-516.

14 Loya N, Lichter H, Barash D, Goldenberg-Cohen N, Strassmann E, Weinberger D. Posterior chamber intraocular lens implantation after capsular tear: ultrasound biomicroscopy evaluation. J Cataract Refract Surg 2001; 27: 1423-1427.

15 Verbruggen KH, Rozema JJ, Gobin L, Coeckelbergh T, De Groot V, Tassignon MJ. Intraocular lens centration and visual outcomes after bag-in-the-lens implantation. J Cataract Refract Surg 2007; 33: 1267-1272. 
16 Gabor SG, Pavilidis MM. Sutureless intrascleral posterior chamber intraocular lens fixation. J Cataract Refract Surg 2007; 33(11): 1851-1854.

17 Maggi R, Maggi C. Sutureless scleral fixation of intraocular lenses. J Cataract Refract Surg 1997; 23(9): 1289-1294.

18 Song A, Scott IU, Flynn Jr HW, Budenz DL. Delayed-onset bleb-associated endophthalmitis: clinical features and visual acuity outcomes. Ophthalmology 2002; 109: 985-991.

19 Price MO, Price Jr FW, Werner L, Berlie C, Mamalis N. Late dislocation of scleral-sutured posterior chamber intraocular lenses. J Cataract Refract Surg 2005; 31: 1320-1326.

20 Heilskov T, Joondeph BC, Olsen KR, Blankenship GW. Late endophthalmitis after transscleral fixation of a posterior chamber intraocular lens. Arch Ophthalmol 1989; 107: 1427.

21 Parekh P, Green WR, Stark WJ, Akpek EK. Subluxation of suture-fixated posterior chamber intraocular lenses: a clinicopathologic study. Ophthalmology 2007; 114: 232-237.

22 Evereklioglu C, Er H, Bekir NA, Borazan M, Zorlu F. Comparison of secondary implantation of flexible open-loop anterior chamber and scleral-fixated posterior chamber intraocular lenses. J Cataract Refract Surg 2003; 29(2): 301-308.

23 Donaldson KE, Gorscak JJ, Budenz DL, Feuer WJ, Benz MS, Forster RK. Anterior chamber and sutured posterior chamber intraocular lenses in eyes with poor capsular support. J Cataract Refract Surg 2005; 31: 903-909.

24 Bellucci R, Pucci V, Morselli S, Bonomi L. Secondary implantation of angle-supported anterior chamber and scleral fixated posterior chamber intraocular lenses. J Cataract Refract Surg 1996; 22: 247-252.

25 Kwong YY, Yuen HK, Lam RF, Lee VY, Rao SK, Lam DS. Comparison of outcomes of primary scleral-fixated versus primary anterior chamber intraocular lens implantation in complicated cataract surgeries. Ophthalmology 2007; 114(1): 80-85.

26 Dadeya S, Kamlesh K, Kumari Sodhi P. Secondary intraocularlens (IOL) implantation: anterior chamber versus scleral fixation long-term comparative evaluation. Eur J Ophthalmol 2003; 13: 627-633.

27 Bayramlar H, Hepsen IF, Cekiç O, Gündüz A. Comparison of the results of primary and secondary implantation of flexible open-loop anterior chamber intraocular lens. Eye 1998; 12: 826-828.

28 Huang YS, Xie LX, Wu XM, Han DS. [Long-term follow-up of flexible open-loop anterior chamber intraocular lenses implantation]. Zhonghua Yan Ke Za Zhi 2006; 42(5): 391-395.

29 Numa A, Nakamura J, Takashima M, Kani K. Long-term corneal endothelial changes after intraocular lens implantation. Anterior vs posterior chamber lenses. Jpn J Ophthalmol 1993; 37: 78-87.

30 Ferguson AW, Malik TY. Pseudophakic posterior iris chafing syndrome. Eye 2003; 17: 451-452.

31 John G, Stark W. Rotation of posterior chamber intraocular lenses for management of lens-associated recurring hyphemas. Arch Ophthalmol 1992; 110: 963-964.

32 Nicholson D. Occult iris erosion: a treatable cause of recurrent hyphema in iris-supported intraocular lenses. Ophthalmology 1982; 89: 113-120.

33 Amino K, Yamakawa R. Long-term results of out-of-the-bag intraocular lens implantation. J Cataract Refract Surg 2000; 26: 266-270.

34 Jacobs PM, Cheng H, Price NC. Pseudophakodonesis and corneal endothelial contact: direct observations by highspeed cinematography. Br J Ophthalmol 1983; 67: 650-654.

35 Jacobi KW, Jagger WS. Physical forces involved in pseudophacodonesis and iridodonesis. Albrecht Von Graefes Arch Klin Exp Ophthalmol 1981; 216: 49-53.

36 Pereira AC, Porfírio Jr F, Freitas LL, Belfort Jr R. Ultrasound energy and endothelial cell loss with stop-and-chop and nuclear preslice phacoemulsification. J Cataract Refract Surg 2006; 32: 1661-1666.

37 Uthoff D, Teichmann KD. Secondary implantation of scleralfixated intraocular lenses. J Cataract Refract Surg 1998; 24: 945-950.

38 Vote BJ, Tranos P, Bunce C, Charteris DG, Da Cruz L. Longterm outcome of combined pars plana vitrectomy and scleral-fixated sutured posterior chamber intraocular lens implantation. Am J Ophthalmol 2006; 141: 308-312.

39 McDonnell PJ, Champion R, Green WR. Location and composition of haptics of posterior chamber intraocular lenses; histopathological study of postmortem eyes. Ophthalmology 1987; 94: 136-142.

40 Teichmann KD, Teichmann IAM. The torque and tilt gamble. J Cataract Refract Surg 1997; 23: 413-418. 